\title{
The role of inflammatory indices in the outcome of COVID-19 cancer patients
}

\author{
Hend A. Nooh ${ }^{1} \cdot$ Mona S. Abdellateif ${ }^{2,6}(1) \cdot$ Lobna Refaat $^{1} \cdot$ Eman Z. Kandeel $^{1} \cdot$ Ahmed Bayoumi $^{3} \cdot$ Mohamed Samra $^{4}$. \\ Medhat Khafagy ${ }^{5}$
}

Received: 20 September 2021 / Accepted: 27 October 2021 / Published online: 8 November 2021

○) Springer Science+Business Media, LLC, part of Springer Nature 2021

\begin{abstract}
To assess the prognostic role of different inflammatory indices on the outcome of cancer patients with COVID-19. Sixtytwo adults and 22 pediatric cancer patients with COVID-19 infection were assessed for the prognostic value of certain inflammatory indices including the neutrophil to lymphocyte ratio (NLR), monocyte to lymphocyte ratio (MLR), platelet to lymphocyte ratio (PLR), derived NLR (dNLR), systemic inflammation index (SII), mean platelet volume to platelet ratio (MPR), C-reactive protein to lymphocyte ratio (CRP/L), aggregate index of systemic inflammation (AISI), systemic inflammation response index (SIRI), and neutrophil to lymphocyte, platelet ratio (NLPR). Data were correlated to patients' outcome regarding ICU admission, and incidence of mortality. Increased CRP/L ratio in adult COVID-19 cancer patients was significantly associated with inferior survival [152 (19-2253) in non-survivors, compared to 27.4 (0.8-681) in survivors $(P=0.033)]$. It achieved a sensitivity $(60 \%)$ and a specificity $(90.2 \%)$ at a cut-off 152 , while it achieved a sensitivity of $60 \%$ and specificity $95.1 \%$ at a cut-off 252 (AUC $0.795, P=0.033$ ). When combining both CRP/L and NLPR for the prediction of poor outcome in adult cancer patients with COVID19, the sensitivity increased to $80 \%$ and the specificity was $70.7 \%$ (AUC $0.805, P=0.027$ ). Increased incidence of ICU admission in pediatric cancer patients associated significantly with the severity of covid19 infection, decreased mean corpuscular hemoglobin $(\mathrm{MCH})<28.3$, increased red cell distribution width $($ RDW $)>16$, lymphopenia $<1.04$, pseudo Pelger-Huet appearance, and PLR $<196.4(P=0.004, P=0.040, P=0.029, P=0$. $0.039, P=0.050$, and $P=0.040$; respectively). The mean corpuscular volume (MCV), $\mathrm{MCH}$, and RDW could be useful prognostic markers for poor outcome in COVID-19 pediatric cancer patients $(P<0.05$ for all). Increased both CRP/L and NLPR associated significantly with poor survival in adult COVID-19 cancer patients, while PLR associated significantly with ICU admission in pediatric COVID-19 cancer patients.
\end{abstract}

Keywords COVID-19 $\cdot$ Inflammation index $\cdot$ Cancer $\cdot$ Pediatric $\cdot$ PLR $\cdot$ CRP/L and NLPR

Mona S. Abdellateif

mona.sayed@nci.cu.edu.eg

1 Clinical Pathology Department, National Cancer Institute, Cairo University, Cairo, Egypt

2 Cancer Biology Department, National Cancer Institute, Cairo University, Cairo, Egypt

3 Pediatric Oncology Department, National Cancer Institute, Cairo University, Cairo, Egypt

4 Medical Oncology Department, National Cancer Institute, Cairo University, Cairo, Egypt

5 Surgical Oncology Department, National Cancer Institute, Cairo University, Cairo, Egypt

6 Medical Biochemistry and Molecular Biology, Cancer Biology Department, National Cancer Institute, Cairo University, Cairo, Egypt

\section{Introduction}

The pandemic of COVID-19 has become a worldwide healthcare problem, as it is responsible for about 62,773 deaths globally in the period between the end of 2019 and the 5th of April 2020 [1]. In fact, the COVID-19 pandemic is considered a life-threatening disease especially in patients who have comorbidities [2,3]. Among them were the cancer patients, who are at a higher risk of developing adverse events including intensive care unit (ICU) admission, mechanical ventilation, and/or death more than patients without cancer [4]. Therefore, it is necessary for COVID-19 cancer patients to undergo special medical care, in addition, more research regarding the diagnosis and management is highly recommended to save these vulnerable patients. 
It had been reported that most of COVID-19 patients have mild to moderate infection, while about $15-20 \%$ of cases develop severe form and require hospitalization, ICU admission, and/or mechanical ventilation [5-7]. A growing body of evidence indicates the important role of the inflammatory response accompanied by the virus infection, which is responsible for the pulmonary complications of COVID-19, that leads to acute respiratory distress syndrome (ARDS), and finally septic shock or multiple organ system failure (MOSF) $[8,9]$. This inflammatory response is formed of uncontrolled production of inflammatory cytokines with the recruitment of inflammatory cells as macrophages and granulocytes that leads to cytokine storm $[9,10]$. Peripheral white blood cell (WBC) count with its subtypes are good predictors for this systematic inflammatory response, and thereby the prognosis of the disease [10]. Many recently published studies demonstrated that many combined ratios of complete blood count (CBC) parameters such as NLR, dNLR, PLR, MLR, and SII could be useful diagnostic and prognostic markers for the severity of COVID-19 patients [11-13]. However, this situation would be different in cancer patients, as they have an incompetent immune system that is caused by either the nature of the cancer itself or the anticancer treatment $[14,15]$.

Therefore, the aim of the current study was to assess the prognostic role of different inflammatory indices including NLR, MLR, dNLR, PLR, SII, MPR, CRP/L, AISI, SIRI, and NLPR in cancer patients with COVID-19 infection. Data were correlated to the clinical features of both adult and pediatric cancer patients. As this may help to find an accurate, early, and accessible marker that could predict the prognosis and outcome of such COVID-19 cancer patients.

\section{Patients and methods}

This is a retrospective cohort study conducted on 84 pediatric and adult patients with different types of cancer and got COVID-19 infection. Those patients were admitted and treated at the National Cancer Institute (NCI) between June 2020 and March 2021. All patients were subjected to full history taking, full clinical examination, laboratory assessment in the form of complete hematological (Sysmex XN1000 and Sysmex XT1800) and coagulation profile, kidney function and liver function tests, serum Ferritin and D-dimer. Also, full radiological assessment especially chest X-ray and computed tomography $(\mathrm{CT})$ on chest. Patients were proved to be COVID-19 positive based on the molecular, laboratory, and radiological findings according to the guidance of the world health organization (WHO) [16]. The adult cancer patients were assessed for the severity of SARS-COV-2 infection according to the WHO classification into; mild infection in patients with mild symptoms and normal imaging findings, moderate COVID-19 infection in patients with fever and lung affection by chest X-ray and CT, while severe infection in patients who had severe respiratory symptoms, respiratory rate $>30 / \mathrm{min}$ and $\mathrm{O}_{2}$ saturation was $<93 \%$ in the rest state [16]. While pediatric cancer patients were classified according to the severity of SARS-COV-2 infection into asymptomatic infection in patients who had no symptom of COVID-19 at any time point, mild infection in patients who had mild symptoms and did not require hospitalization, moderate severity in patients who required inpatients management without ICU care, while severe infection in patients who required ICU care for COVID-19 symptoms [17].

Most of the patients 65/84 (77.4\%) were receiving chemotherapy; 36 (42.9\%) were on induction chemotherapy, 11 (13.1\%) were on maintenance, and $8(9.5 \%)$ patients were on consolidation chemotherapy. While the remaining 28 (33.3\%) patients were post-surgery, and only one was receiving radiotherapy. In addition, there were 40 (47.6\%) patients received intensified chemotherapy according to their risk stratification.

We tried to investigate the association between complete blood cell count (CBC)-derived different inflammatory indices and patients' outcome regarding ICU admission, and incidence of mortality, in both adult and pediatric COVID19 cancer patients.

The inflammatory indices were calculated as follows: NLR (neutrophil/lymphocytes), MLR (monocyte/lymphocyte ratio), PLR (platelet/lymphocyte ratio), dNLR (neutrophils/(white blood cells - neutrophils)), MPR (mean platelet volume/platelet ratio), CRP/L (CRP/lymphocyte ratio), NLPR (neutrophil/(lymphocyte $\times$ platelet ratio)), SII ((neutrophils $\times$ platelets)/lymphocytes), AISI ((neutrophils $\times$ monocytes $\times$ platelets)/lymphocytes, and SIRI ((neutrophils $\times$ monocytes)/lymphocytes).

\section{Statistical analysis}

Data were analyzed using the SPSS package (version 22; SPSS Inc., Chicago, IL, USA). It was tested for normalization using Shapiro test. Continuous variables were expressed as median and interquartile range (IQR), while categorical variables were expressed as frequencies and percentages. Comparisons between groups were performed using Mann-Whitney test and Chi-square test for numerical and categorical variables, respectively. A receiver operating characteristic (ROC) curve analysis was performed to determine the ability of the inflammatory indices for association with mortality in adult and pediatric COVID-19 cancer patients. Univariate and multivariate regression analyses were performed to detect the prognostic value of the inflammatory indices regarding association with ICU admission in COVID-19 adult and pediatric cancer patients. All tests were 
two-tailed and $P$ value $<0.05$ was considered a statistically significant.

\section{Results}

The current study included 84 cancer patients with COVID$19,22(26.1 \%)$ of them were pediatrics [50\% (11/22) were male \& 50\% (11/22) were female], and $62(73.8 \%)$ were adult patients $[62.9 \%(39 / 62)$ were males and $37.1 \%(23 / 62)$ were females, $P=0.320]$. Hematological malignancies were more common than solid tumors in pediatric patients [16 $(72.7 \%)$ vs. $6(27.3 \%)$; respectively], while solid tumors were more commonly observed in adults than hematological malignancies [35 (56.5\%) vs. 27 (43.5\%); respectively, $P=0.025]$. The disease course was progressive in $72.6 \%$ $(45 / 62)$ in adults compared to $68.2 \%(15 / 22)$ in pediatric cancer patients $(P=0.785)$.

The degree of COVID-19 infection in pediatric cancer patients was asymptomatic to mild in $7(31.8 \%)$ patients, moderate in $5(22.7 \%)$, and severe in $10(45.5 \%)$ patients. While in adults, the degree of COVID-19 infection was mild in 26 (41.9\%), moderate in 25 (40.3\%), and severe in $11(17.7 \%)$ patients, $(P=0.033)$. The ICU admission was encountered in 50\% (11/22) of the pediatric patients, compared to $22.6 \%(14 / 62)$ of the adult patients $(P=0.028)$. There were $50 \%(11 / 22)$ of the pediatric cancer patients mechanically ventilated, compared to only $8.1 \%(5 / 62)$ of the adult patients $(P<0.001)$. Neutropenic sepsis was found in $9(10.7 \%)$ patients [4/62 (6.5\%) of adults, and 5/22 (22.7\%) in pediatric patients, $(P=0.049)]$.

Of the adult patients, $14.5 \%(9 / 62)$ had one or more preexisting diseases, including hypertension, cardiovascular disease, and diabetes, compared to only $9.1 \%(2 / 22)$ of pediatric COVID-19 cancer patients who had hypertension $(P=0.575)$. Finally, $40.9 \%(9 / 22)$ of pediatric patients, and $9.7 \%(6 / 62)$ of the adult patients died $(P=0.002)$. The other clinical features of the assessed patients were illustrated in Table 1.

\section{Laboratory findings of the adult and pediatrics COVID-19 cancer patients}

The morphological changes of the monocytes regarding being vacuolated, aggressive, and granular with cytoplasmic tail were significantly detected in pediatric patients $(P=0.035)$, where the monocytes' changes were positive in $19 / 22(86.4 \%)$ and negative in $3 / 22(13.6 \%)$. Meanwhile, in adult COVID-19 cancer patients, the monocytes' changes were positive in 38/62 (61.3\%) and negative in 24/62 (38.7\%). The acute phase reactants, e.g., Ferritin was increased in pediatrics than adults, but it did not reach a significant level [4337 (3610-6180) vs. 72 (10-135);
Table 1 Clinico-pathological features of the patients

\begin{tabular}{|c|c|c|c|}
\hline \multirow[t]{2}{*}{ Clinical variable } & \multicolumn{2}{|l|}{ Patients } & \multirow[t]{2}{*}{$P$ value } \\
\hline & Pediatric (22) & Adult (62) & \\
\hline \multicolumn{4}{|l|}{ Age } \\
\hline Median (IQR) & $11(3-18)$ & $44(19-71)$ & $<0.001$ \\
\hline \multicolumn{4}{|l|}{ Gender } \\
\hline Male & $11(50 \%)$ & $39(62.9 \%)$ & 0.320 \\
\hline Female & $11(50 \%)$ & $23(37.1 \%)$ & \\
\hline \multicolumn{4}{|l|}{ Type of cancer } \\
\hline Hematological malignancies & $16(72.7 \%)$ & $27(43.5 \%)$ & 0.025 \\
\hline Solid tumors & $6(27.3 \%)$ & $35(56.5 \%)$ & \\
\hline \multicolumn{4}{|l|}{ Disease status } \\
\hline Remission & $7(31.8 \%)$ & $17(27.4 \%)$ & 0.785 \\
\hline Stationary or progressed & $15(68.2 \%)$ & $45(72.6 \%)$ & \\
\hline \multicolumn{4}{|l|}{ Degree of COVID infection } \\
\hline Mild & $7(31.8 \%)$ & $26(41.9 \%)$ & $\mathbf{0 . 0 3 3}$ \\
\hline Moderate & $5(22.7 \%)$ & $25(40.3 \%)$ & \\
\hline Severe & $10(45.5 \%)$ & $11(17.7 \%)$ & \\
\hline \multicolumn{4}{|l|}{ ICU admission } \\
\hline Yes & $11(50 \%)$ & $14(22.6 \%)$ & 0.028 \\
\hline No & $11(50 \%)$ & $48(77.4 \%)$ & \\
\hline \multicolumn{4}{|l|}{ Mechanical ventilator } \\
\hline Yes & $11(50 \%)$ & $5(8.1 \%)$ & $<0.001$ \\
\hline No & $11(50 \%)$ & $57(91.9 \%)$ & \\
\hline \multicolumn{4}{|l|}{ Death } \\
\hline No & $13(59.1 \%)$ & $56(90.3 \%)$ & 0.002 \\
\hline Yes & $9(40.9 \%)$ & $6(9.7 \%)$ & \\
\hline \multicolumn{4}{|l|}{ Comorbidities } \\
\hline No & $20(90.9 \%)$ & $53(85.5 \%)$ & 0.575 \\
\hline HTN & $2(9.1 \%)$ & $4(6.5 \%)$ & \\
\hline Cardiac disease & $0(0.0 \%)$ & $4(6.5 \%)$ & \\
\hline DM & $0(0.0 \%)$ & $1(1.6 \%)$ & \\
\hline \multicolumn{4}{|l|}{ Blood stream infection } \\
\hline$-\mathrm{ve}$ & $17(77.3 \%)$ & $57(91.9 \%)$ & 0.118 \\
\hline$+\mathrm{ve}$ & $5(22.7 \%)$ & $5(8.1 \%)$ & \\
\hline \multicolumn{4}{|l|}{ Neutropenic sepsis } \\
\hline No & $17(77.3 \%)$ & $58(93.5 \%)$ & 0.049 \\
\hline Yes & $5(22.7 \%)$ & $4(6.5 \%)$ & \\
\hline \multicolumn{4}{|l|}{ DCL } \\
\hline No & $18(81.8 \%)$ & $57(91.9 \%)$ & 0.232 \\
\hline Yes & $4(18.2 \%)$ & $5(8.1 \%)$ & \\
\hline \multicolumn{4}{|l|}{ Liver disease } \\
\hline No & $19(86.4 \%)$ & $55(88.7 \%)$ & 0.717 \\
\hline Yes & $3(13.6 \%)$ & $7(11.3 \%)$ & \\
\hline \multicolumn{4}{|l|}{ Renal disease } \\
\hline No & $19(86.4 \%)$ & $56(90.3 \%)$ & 0.691 \\
\hline Yes & $3(13.6 \%)$ & $6(9.7 \%)$ & \\
\hline \multicolumn{4}{|l|}{ Duration of hospital stay } \\
\hline Median (IQR) & $11(0-42)$ & $10(0-30)$ & 0.656 \\
\hline$<10$ days & $11(50 \%)$ & $33(55.0 \%)$ & 0.804 \\
\hline$>10$ days & $11(50 \%)$ & $27(45.0 \%)$ & \\
\hline
\end{tabular}

Bold values indicate statistically significant 
respectively, $(P=0.064)]$. Also, there was a significant difference between the pediatric and adult patients regarding the kidney functions laboratory tests including Urea [24 (12-54) vs. $31(13-86)$; respectively, $(P=0.022)]$ and Creatinine $[0.55(0.3-1.2)$ vs. $0.8(0.3-3.6)$; respectively, $(P<0.001)]$. The other different laboratory parameters including Total Leukocyte Count (TLC), Hemoglobin concentration (Hb), Mean Corpuscular Volume (MCV), Mean Corpuscular Hemoglobin (MCH), Red Cell Distribution Width (RDW), Neutrophil, lymphocytes, and monocytes absolute and relative values did not show any statistical difference between the assessed adult and pediatric patients' groups (Table 2).

\section{Inflammatory indices in adult and pediatric COVID-19 cancer patients}

The median NLR in pediatric patients was 1.889 (IQR 0.1-16.6), while in adults it was 2.838 (IQR 0-30.3, $P=0.345)$. The median LMR in pediatric patients was 2.072 (IQR 0.1-18.5), and in adults was 2.550 (IQR $0.4-120, P=0.274)$. The median PLR in pediatric patients was 196.428 (IQR 4.4-2054.5), and in adults, it was 156

Table 2 Laboratory findings of the adult and pediatric COVID-19 cancer patients

\begin{tabular}{|c|c|c|c|c|c|c|c|}
\hline \multirow[t]{2}{*}{ Clinical variable } & \multicolumn{2}{|l|}{ Patients } & \multirow[t]{2}{*}{$P$ value } & \multirow[t]{2}{*}{ Clinical variable } & \multicolumn{2}{|l|}{ Patients } & \multirow[t]{2}{*}{$P$ value } \\
\hline & Pediatric (22) & Adult (62) & & & Pediatric (22) & Adult (62) & \\
\hline TLC & $5.3(.49-12.7)$ & $7.9(.27-31)$ & 0.068 & $\mathrm{MCV}$ & $83.9(70-96.5)$ & $84.9(51-807)$ & 0.749 \\
\hline $\mathrm{Hb}$ & $10.3(7.7-16)$ & $10.9(4.9-16.3)$ & 0.791 & $\mathrm{MCH}$ & $28.3(21.5-34.3)$ & $28.2(19.2-85.4)$ & 0.891 \\
\hline RDW & $16.2(13.3-43.8)$ & $15(11.6-21.2)$ & 0.338 & Normoblast & $0(0-1.3)$ & $0(0-1.3)$ & 0.126 \\
\hline Platelet count & $225(31-724)$ & $284(5-666)$ & 0.583 & MPV & $10(7.6-11)$ & $10.3(6.6-13.1)$ & 0.284 \\
\hline Neutrophil & $1.9(.04-10.9)$ & $4.9(.03-28.6)$ & 0.54 & Neutrophil\% & $47.9(7-86)$ & $65(11-92.4)$ & 0.241 \\
\hline IG & $0.02(0.02-0.53)$ & $0.04(0.01-1.4)$ & 0.650 & $\mathrm{IG} \%$ & $0.6(0.2-18.7)$ & $0.5(0.1-22.1)$ & 0.107 \\
\hline Lymphocytes & $1.04(.12-2.86)$ & $1.7(0.09-4.4)$ & 0.109 & Lymphocytes\% & $21.1(6.9-53.7)$ & $20.5(3-85.3)$ & 0.734 \\
\hline Monocytes & $0.58(.04-1.79)$ & $0.73(.02-4.2)$ & 0.263 & Monocytes\% & $7.9(0.8-71.9)$ & $8.6(1.7-34.5)$ & 0.089 \\
\hline Eosinophil & $0.03(0-1.4)$ & $0.09(0-0.56)$ & 0.192 & Basophil & $0(0-2)$ & $0(0-0.06)$ & 0.247 \\
\hline Giant & & & & Blasts & & & \\
\hline Negative & $10(45.5 \%)$ & $21(33.9 \%)$ & 0.441 & Negative & $20(90.9 \%)$ & $52(83.9 \%)$ & 0.724 \\
\hline Positive & $12(54.5 \%)$ & $41(66.1 \%)$ & & Positive & $2(9.1 \%)$ & $10(16.1 \%)$ & \\
\hline Toxic granulation & & & & Pelger-huet & & & \\
\hline Negative & $15(68.2 \%)$ & $38(61.3 \%)$ & 0.617 & Negative & $8(36.4 \%)$ & $20(32.3 \%)$ & 0.795 \\
\hline Positive & $7(31.8 \%)$ & $24(38.7 \%)$ & & Positive & $14(63.6 \%)$ & $42(67.7 \%)$ & \\
\hline Hypogranulation & & & & Shift to left & & & \\
\hline Negative & $20(90.9 \%)$ & $55(88.7 \%)$ & 0.774 & Negative & $18(81.8 \%)$ & $45(72.6 \%)$ & 0.568 \\
\hline Positive & $2(9.1 \%)$ & $7(11.3 \%)$ & & Positive & $4(18.2 \%)$ & $17(27.4 \%)$ & \\
\hline Mature & & & & Plasmoid & & & \\
\hline Negative & $3(13.6 \%)$ & $10(16.1 \%)$ & 0.781 & Negative & $3(13.6 \%)$ & $13(21.0 \%)$ & 0.543 \\
\hline Positive & $19(86.4 \%)$ & $52(83.9 \%)$ & & Positive & $19(86.4 \%)$ & $49(79.0 \%)$ & \\
\hline Monocytoid \& Ballerina & & & & Vacuolated, aggre & ssive, monocovicyte & & \\
\hline Negative & $8(36.4 \%)$ & $27(43.5 \%)$ & 0.621 & Negative & $3(13.6 \%)$ & $24(38.7 \%)$ & $\mathbf{0 . 0 3 5}$ \\
\hline Positive & $14(63.6 \%)$ & $35(56.5 \%)$ & & Positive & $19(86.4 \%)$ & $38(61.3 \%)$ & \\
\hline LDH & $221(127-762)$ & $237(129-1890)$ & 0.990 & Albumin & $3.4(1.9-4.2)$ & $3.2(1.8-4.6)$ & 0.534 \\
\hline D-Dimer & $0.5(0-123)$ & $4(1-95)$ & 0.414 & Ferritin & 4337 (3610-6180) & $72(10-135)$ & 0.064 \\
\hline CRP & $22.9(0-248)$ & $42(1.8-406)$ & 0.212 & Total bilirubin & $0.45(0.2-2.5)$ & $0.45(0.1-4.7)$ & 0.842 \\
\hline AST & $20.5(9-42)$ & $19(9-275)$ & 0.142 & ALT & $20(8-52)$ & $21(6-280)$ & 0.951 \\
\hline Urea & $24(12-54)$ & $31(13-86)$ & 0.022 & Creatinine & $0.55(.3-1.2)$ & $0.8(0.3-3.6)$ & $<0.001$ \\
\hline PT & $1.12(1-4.1)$ & $1.14(0.96-1.9)$ & 0.849 & & & & \\
\hline
\end{tabular}

Bold values indicate statistically significant

The $P$ value is significant if $<0.05$

$A L T$ alanine transaminase, $A S T$ aspartate transaminase, $C R P$ C- reactive protein, $H b$ hemoglobin concentration, $I G$ immature granulocyte, $L D H$ lactate dehydrogenase, $M C H$ mean corpuscular hemoglobin, $M C V$ mean corpuscular volume, $M P V$ mean platelet volume, $P T$ prothrombin time, $R D W$ red cell distribution width, $T L C$ total leukocyte count 
(IQR 2.7-2322.2, $P=0.101$ ). The median $\mathrm{d}(\mathrm{NLR})$ in pediatric patients was 0.8878 (IQR 0.08-9.50), and in adults it was 1.5874 (IQR $0-12.07 P=0.203$ ). The median SII index in pediatric patients was 291.64 (IQR 1-8154), and in adults it was 615.98 (IQR $0-9752, P=0.303$ ). The median CRP/L in pediatric patients was 55.84 (IQR 0-998.33), and it was 30.92 (IQR 0.79-2253.3, $P=0.985$ ) in adults. The median MPR in pediatric patients was 0.0437 (IQR $0.01-0.35$ ), and it was 0.0342 (IQR $0.01-0.45, P=0.384$ ) in adults. The median NLPR in pediatric patients was 0.0107 (IQR 0-0.07), and in adults was 0.0114 (IQR 0-0.35, $P=0.726)$. The median SIRI in pediatric patients was 0.61 (IQR 0-20.16), while in adults was 1.516 (IQR 0-23.56, $P=0.146)$. The median AISI in pediatric patients was 98.58 (IQR 0-1459.9), while it was 289.51 (IQR 0-8821.9, $P=0.091$ ) in adult COVID-19 cancer patients (Fig. 1).

\section{Association between inflammatory indices and the outcome of the assessed COVID-19 cancer patients}

Patients were categorized according to their outcome regarding ICU admission and mortality.

Increased CRP/L ratio in adult COVID-19 cancer patients was significantly associated with inferior survival, as it was 152 (19-2253) in non-survivors, compared to $27.4(0.8-681)$ in survivors $(P=0.033)$. Other inflammatory indices showed no statistical difference between ICU admitted/non admitted patients nor survivors/non-survivors COVID-19 cancer patients (Table 3).

Regarding COVID-19 pediatric cancer patients, the association between inflammatory indices and patients' outcome showed no statistically significant difference between ICU admitted pediatric patients and non-ICU patients. Also, there were no significant differences between survivors and non-survivors in pediatric COVID-19 cancer patients (Table 4).

The ROC curve analysis of inflammatory indices showed that $\mathrm{CRP} / \mathrm{L}$ associated significantly with increased mortality in adult COVID-19 cancer patients with a sensitivity of $60 \%$ and a specificity of $90.2 \%$ at a cut-off 152 , while it achieved a sensitivity of $60 \%$ and specificity $95.1 \%$ at a cutoff 252 (AUC 0.795, $P=0.033$, Fig. 2). While, when combining both CRP/L and NLPR for the prediction of the poor outcome in adult COVID19 cancer patients, the sensitivity increased to $80 \%$ and the specificity was $70.7 \%$ (AUC 0.805 , $P=0.027$, Table 5). However, ROC analysis did not reveal any statistical significance of the assessed other inflammatory indices for predicting mortality in either adult or pediatric COVID-19 cancer patients (Figs. 2 and 3).

\section{Univariate analysis of risk factors for COVID-19 associated ICU admission in cancer patients}

Increased incidence of ICU admission in pediatric cancer patients associated significantly with increased severity of covid19 infection (OR 72, $P=0.004$ ), as out of the 11 patients who admitted to the ICU, 10 patients had severe COVID-19 infection. Also, increased incidence of ICU admission in pediatric cancer patients associated significantly with decreased MCH below 28.3 (O.R 7.11, $P=0.040$ ), increased RDW $>16$ (OR 12, $P=0.029$ ). In addition, the degree of lymphopenia (lymphocytes $<1.04$ ) associated significantly with poor prognosis (OR 1.77, $P=0$. 0.039). Similarly, abnormality in neutrophils morphology with pseudo Pelger-Huet appearance associated with dismal outcome (OR 8, $P=0.050$ ). The PLR as an inflammatory index $(<196.4$ vs $>196.4)$ significantly predicts poor patients' prognosis (OR 7.11, $P=0.040$, Table 6).
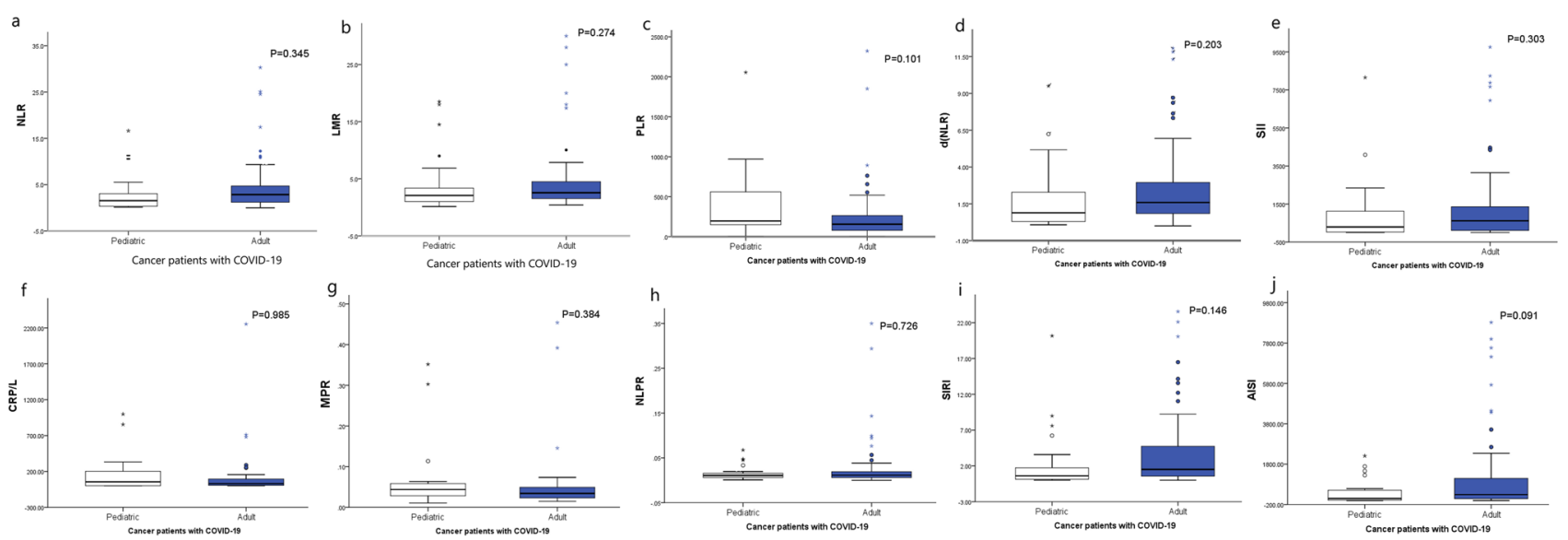

Fig. 1 Expression levels of different inflammatory indices (NLR, MLR, PLR, dNLR, SII, MPR, CRP/L, AISI, SIRI, and NLPR) in adult and pediatric COVID-19 cancer patients 
Table 3 Association between inflammatory indices and patients' outcome in adult cancer patients with COVID-19

\begin{tabular}{lcccccc}
\hline Index & ICU admission & & $P$ value & Death & \multirow{2}{*}{$P$ value } \\
\cline { 2 - 3 } & Yes $(n=14)$ & No $(n=48)$ & & Yes $(n=6)$ & No $(n=56)$ & \\
\hline NLR & $4.8(1.7-24.5)$ & $3.3(0-25.1)$ & 0.957 & $2.99(0.2-24.5)$ & $3.2(0-30.3)$ & 0.437 \\
LMR & $2.6(0.9-10)$ & $2.5(0.4-20)$ & 0.204 & $1.7(0.8-18)$ & $2.5(0.4-25)$ & 0.910 \\
PLR & $241(81-2322)$ & $161(5-519)$ & 0.722 & $128(3.4-386.7)$ & $167(5-2322)$ & 0.821 \\
dNLR & $2.8(1.2-11.3)$ & $2.1(0.12-11.8)$ & 0.762 & $1.1(0.16-11.3)$ & $2.1(0.12-12.1)$ & 0.192 \\
SII & $1301(446-7878)$ & $704(0-6946)$ & 0.423 & $570(1-7878)$ & $754(0-9752)$ & 0.281 \\
CRP/L & $27.8(2-289)$ & $23.9(0.8-250)$ & 0.278 & $152(19-2253)$ & $27.4(0.8-681)$ & $\mathbf{0 . 0 3 3}$ \\
MPR & $0.03(0.01-0.05)$ & $0.04(.02-1.96)$ & 0.072 & $0.0(0.03-0.03)$ & $0.04(.01-1.96)$ & 0.595 \\
NLPR & $0.01(0-0.08)$ & $0.01(0-1.7)$ & 0.915 & $0.04(0-0.08)$ & $0.01(0-1.7)$ & 0.408 \\
SIRI & $2.9(0.2-23.6)$ & $2(0-20.1)$ & 0.845 & $12(0.5-23.6)$ & $2(0-20.1)$ & 0.802 \\
AISI & $1211(39-7960)$ & $501(.01-8822)$ & 0.557 & $3866(169-7963)$ & $501(.01-8822)$ & 0.341 \\
\hline
\end{tabular}

Bold value indicates statistically significant

The $P$ value is significant if $<0.05$

AISI aggregate index of systemic inflammation, $C R P / L$ C-reactive protein to lymphocyte ratio, $d N L R$ derived neutrophil to lymphocyte ratio, $M L R$ monocyte to lymphocyte ratio, $M P R$ mean platelet volume to platelet ratio, $N L P R$ neutrophil to lymphocyte, platelet ratio, $N L R$ the neutrophil to lymphocyte ratio, $P L R$ platelet to lymphocyte ratio, SII systemic inflammation response index, and SIRI systemic inflammation response index
Table 4 Association between inflammatory indices and patients' outcome in pediatric cancer patients with COVID-19

\begin{tabular}{|c|c|c|c|c|c|c|}
\hline \multirow[t]{2}{*}{ Index } & \multicolumn{2}{|l|}{ ICU admission } & \multirow[t]{2}{*}{$P$ value } & \multicolumn{2}{|l|}{ Death } & \multirow[t]{2}{*}{$P$ value } \\
\hline & Yes $(n=11)$ & No $(n=11)$ & & Yes $(n=9)$ & No $(n=13)$ & \\
\hline NLR & $2.9(0.2-11.3)$ & $2(0.3-10.6)$ & 0.718 & $2.9(0.2-11.3)$ & $2(0.3-10.6)$ & 0.973 \\
\hline LMR & $1.9(0.5-3.1)$ & $1.4(0.3-3.4)$ & 0.768 & $1.9(0.5-3.1)$ & $1.4(.3-3.4)$ & 0.713 \\
\hline PLR & $176(9.5-862)$ & 604 (119-970) & 0.250 & $176(9.5-862)$ & 604 (119-970) & 0.713 \\
\hline dNLR & $2(0.1-3.6)$ & $0.5(0.2-6.2)$ & 0.974 & $2(0.1-3.6)$ & $0.5(0.2-6.2)$ & 0.973 \\
\hline SII & $863(7-8154)$ & $302(119-2344)$ & 0.718 & $863(7-8154)$ & $302(119-2344)$ & 0.920 \\
\hline $\mathrm{CRP} / \mathrm{L}$ & $2.9(0.8-203)$ & $54.8(0-332)$ & 0.600 & $2.9(0.79-203)$ & $54.8(0-332)$ & 0.223 \\
\hline MPR & $0.03(0.01-0.35)$ & $0.05(0.03-.06)$ & 0.560 & $0.03(0.01-0.35)$ & $0.05(0.03-.06)$ & 0.674 \\
\hline NLPR & $0.01(0-0.02)$ & $0.01(0-0.05)$ & 0.250 & $0.01(0-0.02)$ & $0.01(0-0.05)$ & 0.243 \\
\hline SIRI & $1.5(0.12-20)$ & $0.72(0.07-7.6)$ & 0.870 & $1.5(0.12-20)$ & $0.72(0.07-7.6)$ & 0.764 \\
\hline AISI & $492(9-14,594)$ & $139(24-1687)$ & 0.718 & $492(9-14,595)$ & $140(24-1688)$ & 0.973 \\
\hline
\end{tabular}

The $P$ value is significant if $<0.05$

AISI aggregate index of systemic inflammation, $C R P / L$ C-reactive protein to lymphocyte ratio, $d N L R$ derived neutrophil to lymphocyte ratio, $M L R$ monocyte to lymphocyte ratio, $M P R$ mean platelet volume to platelet ratio, $N L P R$ neutrophil to lymphocyte, platelet ratio, $N L R$ the neutrophil to lymphocyte ratio, $P L R$ platelet to lymphocyte ratio, SII systemic inflammation response index, and SIRI systemic inflammation response index
However, univariate analysis for COVID-19 associated ICU admission in adult cancer patients revealed that disturbed conscious level (DCL) associated significantly with inferior outcome of the patients (OR 11.1, $P=0.046)$. The other clinicopathological features assessed did not show any significant difference (Table 7).

\section{The prognostic role of RBCs indices in COVID-19 cancer patients}

The ROC analysis was performed to evaluate the role MCV, $\mathrm{MCH}$, and RDW in predicting the outcome in COVID-19 cancer patients. It showed that the sensitivity, specificity, 

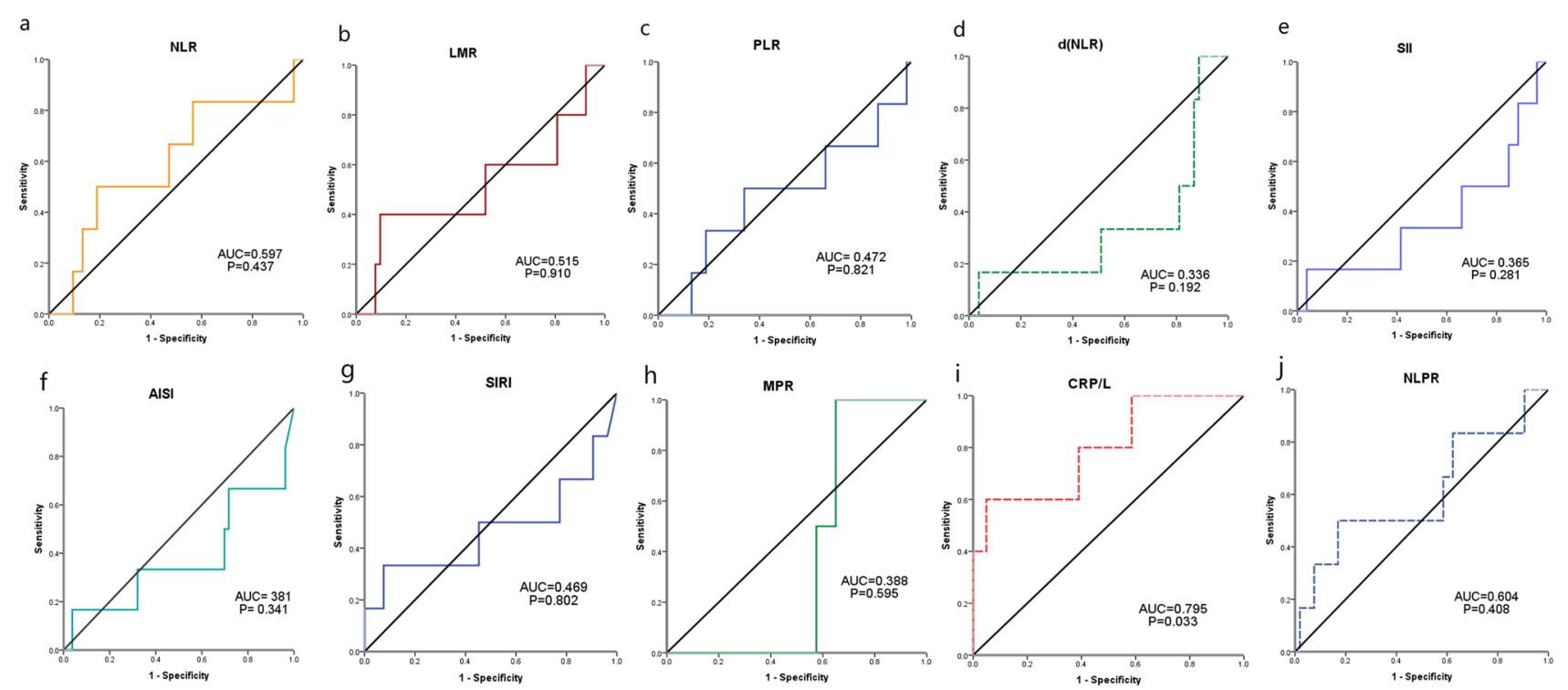

Fig. 2 ROC curve analysis of inflammatory indices (NLR, MLR, PLR, dNLR, SII, AISI, SIRI, MPR, CRP/L, and NLPR) for association with mortality in adult COVID-19 cancer patients

Table 5 ROC curve analysis of inflammatory indices for association with mortality in adult cancer patients

\begin{tabular}{llllll}
\hline & AUC & Cut-off & $\begin{array}{l}\text { Sensi- } \\
\text { tivity } \\
(\%)\end{array}$ & Specificity (\%) & $P$ value \\
\hline CRP/L & 0.795 & 152 & 60 & 90.2 & $\mathbf{0 . 0 3 3}$ \\
& 0.795 & 252 & 60 & 95.1 & \\
NLPR & 0.604 & 0.028 & 50 & 83 & 0.408 \\
CRP/L + NLPR & 0.805 & - & 80 & 70.7 & $\mathbf{0 . 0 2 7}$ \\
\hline
\end{tabular}

Bold values indicate statistically significant

and AUC of MCV were $90 \%, 100 \%$, and 0.926 ; respectively, $(P=0.001)$, at a cut-off $(83.6 \mathrm{fL}), \mathrm{MCH}$ were $81.8 \%$, $72.7 \%$, and 0.802 ; respectively, $(P=0.017)$, at a cut-off $(27.7$ $\mathrm{Pg}$ ), and the RDW were $72.7 \%, 90 \%$, and 0.841 ; respectively, $(P=0.008)$ at a cut-off $(16.3 \mathrm{fL})$, for association with increased incidence of ICU admission in pediatric COVID19 cancer patients (Fig. 4A-C). Where the mean Hb concentration for these children was $9.9 \pm 2.5 \mathrm{gm} / \mathrm{dl}$. While for increased mortality rates, the sensitivity, specificity, and AUC of MCV were $88.9 \%, 92.3 \%$, and 0.889 ; respectively, $(P=0.002)$, at a cut-off ( $84.4 \mathrm{fL}), \mathrm{MCH}$ were $77.8 \%, 61.5 \%$, and 0.752 ; respectively, $(P=0.049)$ at a cut-off $(27.7 \mathrm{Pg})$, and for RDW, they were $77.8 \%, 83.3 \%$, and 0.778 ; respectively, $(P=0.033)$ at a cut-off ( $16.3 \mathrm{fL}$, Fig. 4E-G). Regarding the combination of $\mathrm{MCV}, \mathrm{MCH}$, and RDW together in pediatric COVID-19 cancer patients, it showed a sensitivity (81.8\%), specificity (100\%), AUC (0.927) for association with ICU admission $(P=0.001$, Fig. $4 \mathrm{D})$, and the mean $\mathrm{Hb}$ concentration for these children was $10.4 \pm 2.5 \mathrm{gm} / \mathrm{dl}$. While it achieved a sensitivity (77.8\%), specificity (83.3\%), AUC $(0.843)$ for association with increased incidence of mortality $(P=0.009$, Fig. $4 \mathrm{H})$. However, these parameters did not show any significant association with the outcome of adult COVID-19 cancer patients (data not shown).

\section{Discussion}

Many studies have reported the useful diagnostic and prognostic roles of different inflammatory indices in COVID-19 infection in noncancer population [11-13]; however, their role in COVID-19 cancer patients is not well assessed. In the current study, we could not find any significant impact of NLR, MLR, dNLR, SII, MPR, AISI, and SIRI on the outcome of both adult and pediatric cancer patients with COVID-19 infection, which was in contrast to that observed in COVID-19 non-cancer patients [18-20]. Meanwhile, other studies demonstrated that increased levels of NLR, PLR, and SII associated significantly with death in patients with lung, bladder, and cervical cancer [21-23]. This discrepancy in the results could be explained by that cancer patients with COVID-19 viral infection have underlying risk factors regarding the type of cancer, as well as the type of treatment, e.g., chemotherapy, radiotherapy, or cytotoxic drugs with their known myelosuppressive and immunosuppressive consequences [24]. As this myelosuppressive and/ or immunosuppressive effect causes reduction in the neutrophil, monocyte, platelets, RBCs, T-cell, and B-cell populations [25], which affects their derived inflammatory indices. Therefore, it will eventually elucidate a different response to 

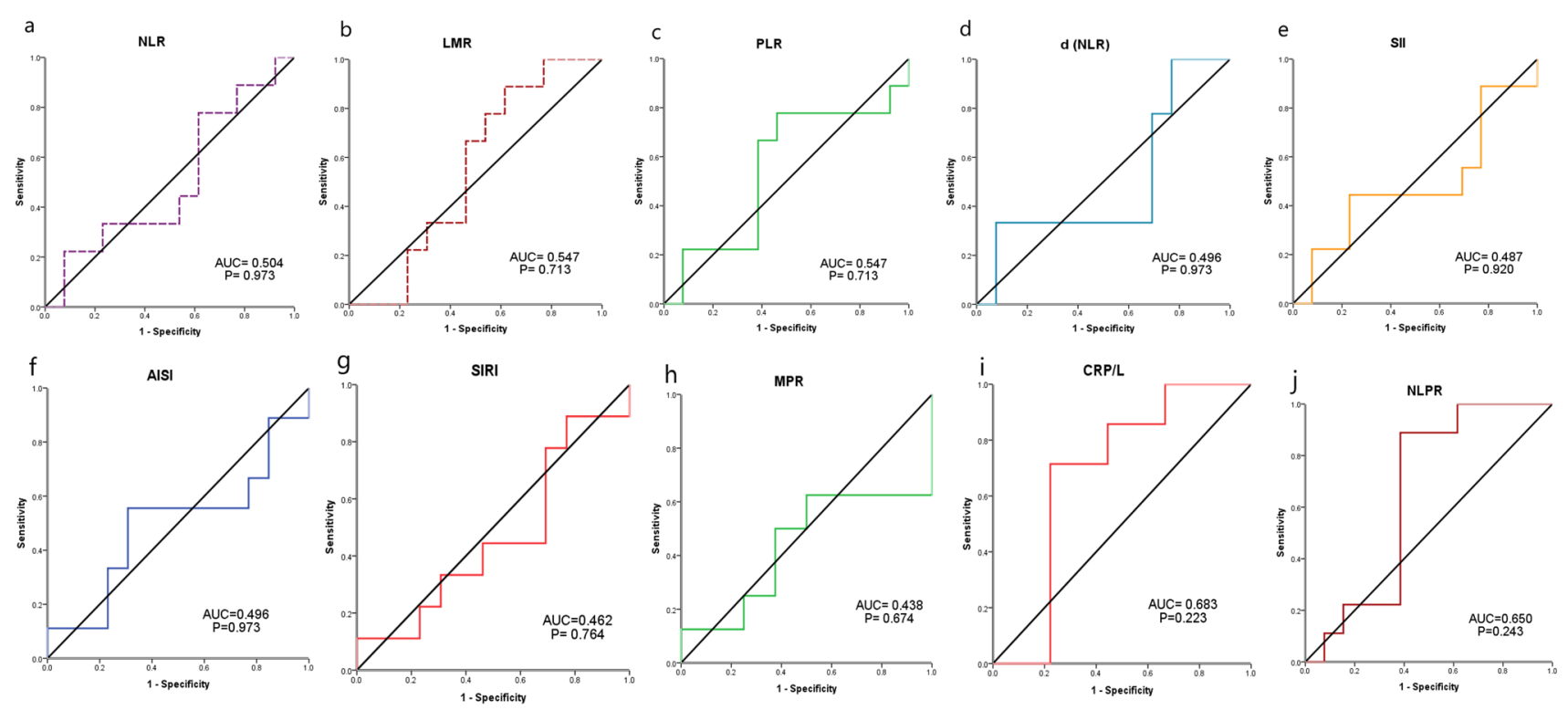

Fig. 3 ROC curve analysis of inflammatory indices (NLR, MLR, PLR, dNLR, SII, AISI, SIRI, MPR, CRP/L, and NLPR) for association with mortality in pediatric cancer patients

the COVID-19 infection or its treatment, unlike in COVID19 non-cancer patients.

Moreover, many recent series reported that cancer patients infected with COVID-19 had more severe outcomes compared to those noncancer COVID-19 patients, especially in those with hematological or lung malignancies [24, 26]. Mehta et al. demonstrated increased case fatality rate (CFR) in cancer patients with COVID-19 infection, it was 37\% for hematologic malignancies and $25 \%$ for solid tumors. They proposed this high CFR in cancer patients with COVID-19 might be due to the presence of co-morbidities associated with cancer patients, or due to the myelosuppressive effect of the anticancer treatment received. Moreover, they also concluded that COVID-19 infection could increase the risk of mortality regardless of the cancer type [24].

The present study demonstrated that increased CRP/L ratio was the only index associated significantly with lower survival in adult COVID-19 cancer patients. Furthermore, these data were confirmed by the ROC curve analysis which showed that $\mathrm{CRP} / \mathrm{L}$ associated significantly with increased mortality in adult COVID-19 cancer patients with a sensitivity of $60 \%$ and a specificity of $90.2 \%$ at a cut-off 152 , and the specificity increased to $95.1 \%$ at a cut-off 252 . While, when combining both CRP/L and NLPR for the prediction of the poor outcome in adult COVID19 cancer patients, the sensitivity increased to $80 \%$ and the specificity was $70.7 \%$ (AUC 0.805). Therefore, increased both CRP/L and NLPR could be useful prognostic markers for the prediction of poor outcome in adult COVID-19 cancer patients. These data are in agreement with many recent reports concluded that decreased lymphocyte to $\mathrm{C}$-reactive protein ratio is considered a predictor factor for poor outcome and mortality in COVID-19 patients [19, 27, 28]. The CRP is an inflammatory marker that synthesized in the liver, and it is considered an important inflammatory marker for bacterial infection [28]. In addition, it responds to the inflammatory cytokines produced by the activated monocytes or macrophages after infection [29]. Hence, the serum level of CRP could reflect the severity of inflammation and consequently the cytokine storm associated with COVID-19 severity [30-32]. Though, the increased serum level of CRP is normally lacking in viral infection, Paces and his colleagues tried to explain this phenomenon in their review. They proposed that the association of increased serum level of CRP with COVID-19 severity is attributed to the development of the macrophage activation syndrome together with the increased production of interleukin-6, which are responsible for the deterioration of the COVID-19 patients [33].

In contrary to our results, Lee et al. [34], investigated the hematological and biochemical parameters prior to and during coronavirus disease 2019 in cancer patients. They found that higher neutrophil count and higher NLR were significantly associated with increased mortality. This difference could be explained by the small number of patients included in the current study (84 patients) compared to 302 patients recruited in their study. However, in line with the present data, they could not find a significant impact of disease stage, neutropenia or lymphopenia on COVID-19 adult cancer patients' outcomes. Though these findings are contradictory to that observed by Feng et al. [35], in their meta-analysis, that increased neutrophil count and lymphopenia $\left(<1 \times 10^{9} / 1\right)$ associated with the severity of COVID-19 
Table 6 Bivariable regression models of potential prognostic variables associated with ICU admission in COVID-19 pediatric cancer patients

\begin{tabular}{|c|c|c|c|c|}
\hline & \multirow[t]{2}{*}{ Odds ratio } & \multicolumn{2}{|l|}{$95 \% \mathrm{CI}$} & \multirow[t]{2}{*}{$P$ value } \\
\hline & & Lower & Upper & \\
\hline Gender male vs female & 2.917 & 0.442 & 19.234 & 0.266 \\
\hline Disease (progression vs remission) & 1.500 & 0.189 & 11.927 & 0.702 \\
\hline $\begin{array}{l}\text { Degree of COVID-19 (sever vs moderate } \\
\text { or mild) }\end{array}$ & 72.000 & 3.841 & 1349.547 & 0.004 \\
\hline DCL (+ve vs -ve) & 3.429 & 0.287 & 40.946 & 0.330 \\
\hline $\begin{array}{l}\text { Blood stream infection } \\
(+ \text { ve vs }- \text { ve })\end{array}$ & 1.500 & 0.189 & 11.927 & 0.702 \\
\hline Comorbidities (+ve vs -ve) & 2.000 & 0.150 & 26.734 & 0.600 \\
\hline Liver disease (+ve vs - ve) & 2.000 & 0.150 & 26.734 & 0.600 \\
\hline $\begin{array}{l}\text { Type of cancer } \\
\text { Hematological vs solid }\end{array}$ & 2.000 & 0.250 & 15.991 & 0.513 \\
\hline TLC $(<10$ vs $>10)$ & 2.000 & 0.150 & 26.734 & 0.600 \\
\hline $\mathrm{Hb}(<10$ vs $>10)$ & 1.867 & 0.283 & 12.310 & 0.517 \\
\hline $\operatorname{MCV}(<90$ vs $>90)$ & .000 & .000 & & 0.999 \\
\hline $\mathrm{MCH}(<28.3$ vs $>28.3)$ & 7.111 & 1.089 & 46.441 & 0.040 \\
\hline RDW (> 16 vs < 16) & 12.000 & 1.294 & 111.323 & 0.029 \\
\hline $\operatorname{NRBC}(<1$ vs $>1)$ & .000 & 0.000 & & 0.999 \\
\hline PLTs $(>150$ vs $<150)$ & 2.000 & 0.312 & 12.840 & 0.465 \\
\hline $\operatorname{MPV}(<10$ vs $>10)$ & 2.667 & 0.347 & 20.508 & 0.346 \\
\hline Giant (+ve vs -ve) & 1.250 & 0.205 & 7.615 & 0.809 \\
\hline Neutrophil $>7.5$ vs $<7.5$ & 2.000 & 0.150 & 26.734 & 0.600 \\
\hline Neutrophil $<70$ vs $>70$ & 1.143 & 0.126 & 10.386 & 0.906 \\
\hline Toxicgran (+ve vs -ve) & 1.333 & 0.204 & 8.708 & 0.764 \\
\hline Pelger-huet (+ve vs -ve) & 8.000 & 1.001 & 63.963 & $\mathbf{0 . 0 5 0}$ \\
\hline Hypogranulation (+ve vs -ve) & .000 & .000 & & 0.999 \\
\hline Shift to left (-ve vs +ve) & 2.571 & 0.192 & 34.473 & 0.476 \\
\hline $\operatorname{IGRc}(1)$ & 2.000 & 0.134 & 29.808 & 0.615 \\
\hline Lymphocyte (<1.04 vs $>1.04)$ & 1.77 & 56.123 & 1.105 & 0.039 \\
\hline Lymphocyte \% (>21.1 vs < 21.1) & 5.4 & 0.088 & 0.778 & 37.505 \\
\hline Mature (+ve vs -ve) & 0.500 & 0.037 & 6.683 & 0.600 \\
\hline Plasmoid (+ve vs -ve) & 0.500 & 0.037 & 6.683 & 0.600 \\
\hline Monocytoid (+ve vs -ve) & 1.333 & 0.204 & 8.708 & 0.764 \\
\hline Monocyte $(<1$ vs $>1)$ & 3.429 & 0.287 & 40.946 & 0.330 \\
\hline Monocyte $\%(<10$ vs $>10)$ & 1.200 & 0.194 & 7.441 & 0.845 \\
\hline Vacuolated (+ve vs -ve) & 2.571 & 0.192 & 34.473 & 0.476 \\
\hline $\mathrm{PT}(>1$ vs $<1)$ & 3.333 & 0.384 & 28.959 & 0.275 \\
\hline $\mathrm{CRP}(>6$ vs $<6)$ & 1.905 & 0.340 & 10.667 & 0.464 \\
\hline LDH $(>220$ vs $<220)$ & 2.519 & 0.460 & 13.801 & 0.287 \\
\hline Albumin $(<3.5$ vs $>3.5)$ & 3.000 & 0.562 & 16.013 & 0.199 \\
\hline $\operatorname{ALT}(<55$ vs $>55)$ & 6.545 & 0.541 & 79.232 & 0.140 \\
\hline $\operatorname{AST}(<34$ vs $>34)$ & 1.937 & 0.396 & 9.491 & 0.415 \\
\hline Total bilirubin $(<1.2$ vs $>1.2)$ & 2.000 & 0.146 & 27.447 & 0.604 \\
\hline Ceartnin $(<1.25$ vs $>1.25)$ & 1.500 & 0.241 & 9.345 & 0.664 \\
\hline Urea $(<45$ vs $>45)$ & 1.212 & 0.212 & 6.935 & 0.829 \\
\hline $\operatorname{NLR}(<1.89$ vs $>1.89)$ & 1.440 & 0.269 & 7.721 & 0.675 \\
\hline LMR (> 2.07 vs <2.07) & 1.400 & 0.256 & 7.714 & 0.670 \\
\hline PLR (<196.4 vs > 196.4) & 7.111 & 1.089 & 46.441 & 0.040 \\
\hline dNLR $(>0.89$ vs $<0.89$ ) & 3.062 & 0.539 & 17.401 & 0.207 \\
\hline SII (>291.6 vs < 291.6) & 1.440 & 0.269 & 7.714 & 0.670 \\
\hline CRP/L (<55.8 vs $>55.8)$ & 2.778 & 0.367 & 21.029 & 0.323 \\
\hline
\end{tabular}


Table 6 (continued)

\begin{tabular}{lccrc}
\hline & Odds ratio & \multicolumn{2}{l}{$95 \% \mathrm{CI}$} & \multirow{2}{*}{$P$ value } \\
\cline { 3 - 4 } & & \multicolumn{1}{l}{ Lower } & Upper & \\
\hline MPR $(>0.044$ vs $<0.044)$ & 1.667 & 0.227 & 12.221 & 0.615 \\
SIRI $(>0.61$ vs $<0.61)$ & 1.440 & 0.269 & 7.714 & 0.670 \\
AISI $(>98.5$ vs $<98.5)$ & 1.440 & 0.269 & 7.714 & 0.670 \\
NLPR $(<0.012$ vs $>0.012)$ & 3.062 & 0.539 & 17.401 & 0.207 \\
\hline
\end{tabular}

Bold values indicate statistically significant

The $P$ value is significant if $<0.05$

AISI aggregate index of systemic inflammation, $A L T$ alanine transaminase, AST aspartate transaminase, $C R P$ C- reactive protein, $C R P / L C R P$ to lymphocyte ratio, $d N L R$ derived neutrophil to lymphocyte ratio, $H b$ hemoglobin concentration, $I G$ immature granulocyte, $L D H$ lactate dehydrogenase, $M C H$ mean corpuscular hemoglobin, $M C V$ mean corpuscular volume, $M L R$ monocyte to lymphocyte ratio, $M P R$ mean platelet volume to platelet ratio, $M P V$ mean platelet volume, $N L P R$ neutrophil to lymphocyte, platelet ratio, $N L R$ the neutrophil to lymphocyte ratio, $P L R$ platelet to lymphocyte ratio, $P T$ prothrombin time, $R D W$ red cell distribution width, SII systemic inflammation response index, and SIRI systemic inflammation response index, $T L C$ total leukocyte count

infection in non-cancer patients. However, the explanation could be that cancer patients already had lymphopenia prior to infection with COVID-19, which is responsible for lack of significant association with the COVID-19 severity. Also, it made cancer patients liable for more severe COVID-19 infection and poorer outcome rather than non-cancer patients [34]. In addition to the presence of neutropenic sepsis which contributed to the neutropenia encountered in our cohort of cancer patients. On the other hand, regarding the recruited pediatric cancer patients, children with lymphopenia $\left(<1.04 \times 10^{9} / \mathrm{l}\right)$ were significantly at a higher risk for ICU admission 1.77 times more than in COVID-19 pediatric cancer patients who had lymphocytes more than $1.04 \times 10^{9} / 1$. This finding indicates that there is a difference between children and adults regarding both innate and adaptive immune responses [36, 37]. Moreover, in this issue, Dong et al. [38], demonstrated in their study that children are more prone to respiratory infections, and thus may have higher levels of antibodies against the virus than adults, or that their developing immune systems may react to pathogens differentially than adult immune system.

It had been reported that children showed a different disease course for COVID-19 rather than in adults [39]. Despite the increasing number of pediatric cancer case with COVID-19 infection, little is known about the impact of the hematological and laboratory profiles on the outcome of these patients [40]. In this context, the present data showed that that there was no significant association between the assessed inflammatory indices and the outcome of COVID-19 pediatric cancer patients, except for the PLR. Children with PLR lower than 196.4 were significantly 7.1 times more liable for ICU admission rather than those who had PLR > 196.4. As PLR is considered as an indicator of inflammation and cytokine storm, hence associated with the severity of COVID-19 infection, and consequently poor outcome [41].

Moreover, Increased incidence of ICU admission in pediatric cancer patients associated significantly with the severity of covid19 infection (OR 7), decreased MCH below 28.3, increased RDW $>16$, lymphopenia (lymphocytes $<1.04$ ), and presence of abnormality in neutrophils' morphology with pseudo Pelger-Huet appearance associated with dismal outcome. These data are consistent with Ma et al. [42] who concluded that lymphopenia and neutrophil abnormality could predict computed tomography (CT) results in pediatric COVID-19 patients. Similarly, other recently published studies reported the association of peripheral pseudo PelgerHuet appearance and the severity of COVID-19 viral infection [43-45].

Interestingly, the present study demonstrated the important prognostic role of $\mathrm{MCV}, \mathrm{MCH}$, and RDW in predicting the outcome of pediatric COVID-19 cancer patients. As these markers $(\mathrm{MCV}<83.6 \mathrm{fL}, \mathrm{MCH}<27.7 \mathrm{Pg}$, and RDW $>16.3 \mathrm{fL}$ ) could possibly predict the incidence of ICU admission and/or death in these patients. Regarding the combination of $\mathrm{MCV}, \mathrm{MCH}$, and RDW together in pediatric COVID-19 cancer patients, it showed a sensitivity (81.8\%), specificity (100\%), and AUC (0.927) for association with ICU admission. While it achieved $77.8 \%$ sensitivity, $83.3 \%$ specificity, and AUC of 0.843 for association with increased incidence of mortality. However, these parameters did not show any significant association with the outcome of adult COVID-19 cancer patients. These data are partially comparable to that found by Wang et al. [46], who performed their study on adult non-cancer patients with COVID-19 infection, and reported that $\mathrm{MCV}$ and $\mathrm{MCH}$ were significantly lower in COVID-19 patients with poor outcome than in the good outcome group. Also, they reported that RDW was 
Table 7 Bivariable regression models of potential prognostic variables associated with ICU admission in COVID-19 adult cancer patients

\begin{tabular}{|c|c|c|c|c|}
\hline & \multirow[t]{2}{*}{ Odds ratio } & \multicolumn{2}{|l|}{$95 \%$ CI } & \multirow[t]{2}{*}{$P$ value } \\
\hline & & Lower & Upper & \\
\hline Gender (male vs female) & 1.071 & 0.293 & 3.921 & 0.917 \\
\hline Disease (progression vs remission) & 1.091 & 0.277 & 4.296 & 0.901 \\
\hline $\begin{array}{l}\text { Degree of COVID-19 (sever vs moderate } \\
\text { or mild) }\end{array}$ & 3.254 & 0.808 & 13.753 & 0.088 \\
\hline DCL (+ve vs -ve) & 11.100 & 1.039 & 118.566 & 0.046 \\
\hline Blood stream infection (+ve vs -ve) & 3.273 & 0.412 & 26.014 & 0.262 \\
\hline Comorbidities (+ve vs -ve) & 1.600 & 0.337 & 7.593 & 0.554 \\
\hline Liver disease (+ve vs -ve) & 3.500 & 0.610 & 20.097 & 0.160 \\
\hline Renal disease (+ve vs -ve) & 1.029 & 0.097 & 10.853 & 0.981 \\
\hline $\begin{array}{l}\text { Type of cancer } \\
\text { Solid vs Hematological }\end{array}$ & 1.821 & 0.477 & 6.957 & 0.381 \\
\hline $\operatorname{TLC}(<10$ vs $>10)$ & 1.648 & 0.458 & 5.928 & 0.444 \\
\hline $\mathrm{Hb}(<10$ vs $>10)$ & 1.296 & 0.367 & 4.583 & 0.687 \\
\hline $\operatorname{MCV}(<90$ vs $>90)$ & 6.094 & 0.758 & 55.732 & 0.095 \\
\hline $\mathrm{MCH}(<28.2$ vs $>28.2)$ & 1.944 & 0.534 & 7.079 & 0.313 \\
\hline RDW $(>16$ vs $<16)$ & 1.179 & 0.317 & 4.384 & 0.806 \\
\hline $\operatorname{NRBC}(<1$ vs $>1)$ & 1.091 & 0.103 & 11.527 & 0.942 \\
\hline PLTs $(>150$ vs $<150$ ) & 1.358 & 0.313 & 5.897 & 0.683 \\
\hline MPV (<10 vs $>10)$ & 1.909 & 0.453 & 8.044 & 0.378 \\
\hline Giant (+ve vs -ve) & 1.244 & 0.313 & 4.954 & 0.756 \\
\hline Blast (+ve vs -ve) & 2.550 & 0.487 & 13.340 & 0.268 \\
\hline Neutrophil ( $<7.5$ vs $>7.5$ ) & 1.156 & 0.289 & 4.618 & 0.838 \\
\hline Neutrophil $\%(>70$ vs < 70) & 1.432 & 0.369 & 5.551 & 0.604 \\
\hline Toxic granulation (+ve vs $-\mathrm{ve})$ & 2.424 & 0.573 & 10.252 & 0.229 \\
\hline Pelger-huet (+ve vs -ve) & 3.214 & 0.841 & 12.283 & 0.088 \\
\hline Hypo-granulation (+ve vs -ve) & .471 & 0.070 & 3.194 & 0.441 \\
\hline Shift to left (-ve vs +ve) & 2.538 & 0.485 & 13.279 & 0.270 \\
\hline Lymphocyte $(>3.5$ vs $<3.5$ ) & 6.364 & 0.525 & 77.079 & 0.146 \\
\hline Lymphocyte $\%$ (>35\% vs <35\%) & 1.051 & 0.266 & 4.145 & 0.944 \\
\hline Mature (+ve vs -ve) & 2.550 & 0.487 & 13.340 & 0.268 \\
\hline Plasmoid (+ve vs -ve) & .805 & 0.145 & 4.476 & 0.804 \\
\hline Monocytoid (+ve vs -ve) & 2.000 & 0.559 & 7.151 & 0.286 \\
\hline Monocyte $(<1$ vs $>1)$ & 1.571 & 0.287 & 8.595 & 0.602 \\
\hline Monocyte $\%(<10$ vs $>10)$ & 1.600 & 0.371 & 6.906 & 0.529 \\
\hline Vacuolated (+ve vs -ve) & 1.071 & 0.293 & 3.921 & 0.917 \\
\hline $\mathrm{PT}(>1$ vs $<1)$ & 3.333 & 0.384 & 28.959 & 0.275 \\
\hline $\mathrm{CRP}(>6$ vs $<6)$ & 1.905 & 0.340 & 10.667 & 0.464 \\
\hline $\mathrm{LDH}(>220$ vs $<220)$ & 2.519 & 0.460 & 13.801 & 0.287 \\
\hline Albumin $(<3.5$ vs $>3.5)$ & 3.000 & 0.562 & 16.013 & 0.199 \\
\hline $\operatorname{ALT}(<55$ vs $>55)$ & 6.545 & 0.541 & 79.232 & 0.140 \\
\hline AST $(<34$ vs $>34)$ & 1.937 & 0.396 & 9.491 & 0.415 \\
\hline Total bilirubin $(<1.2$ vs $>1.2)$ & 2.160 & 0.228 & 20.492 & 0.502 \\
\hline Ceartnin $(<1.25$ vs $>1.25)$ & 1.500 & 0.241 & 9.345 & 0.664 \\
\hline Urea $(<45$ vs $>45)$ & .825 & 0.144 & 4.725 & 0.829 \\
\hline $\operatorname{NLR}(<2.8$ vs $>2.8)$ & 1.524 & 0.455 & 5.109 & 0.495 \\
\hline LMR ( $>2.55$ vs $<2.55)$ & 2.274 & 0.653 & 7.920 & 0.197 \\
\hline $\operatorname{PLR}(>156$ vs $<156)$ & 1.524 & 0.455 & 5.109 & 0.495 \\
\hline dNLR $(<1.59$ vs $>1.59)$ & 1.045 & 0.315 & 3.470 & 0.942 \\
\hline SII $(>615.9$ vs $<615.9)$ & 1.524 & 0.455 & 5.109 & 0.495 \\
\hline CRP/L (>30.9 vs < 30.9) & 1.240 & 0.342 & 4.487 & 0.744 \\
\hline
\end{tabular}


Table 7 (continued)

\begin{tabular}{lllrl}
\hline & Odds ratio & \multicolumn{2}{l}{$95 \% \mathrm{CI}$} & $P$ value \\
\cline { 3 - 4 } & & Lower & Upper & \\
\hline MPR $(<0.034$ vs $>0.034)$ & 3.000 & 0.655 & 13.747 & 0.157 \\
NLPR $(<0.0114$ vs $>.0114)$ & 1.524 & 0.455 & 5.109 & 0.495 \\
SIRI $(>1.52$ vs $<1.52)$ & 1.045 & 0.315 & 3.470 & 0.942 \\
AISI $(>289.5$ vs $<289.5)$ & 1.045 & 0.315 & 3.470 & 0.942 \\
\hline
\end{tabular}

Bold value indicates statistically significant

The $P$ value is significant if $<0.05$

AISI aggregate index of systemic inflammation, $A L T$ alanine transaminase, AST aspartate transaminase, $C R P$ C- reactive protein, $C R P / L \mathrm{CRP}$ to lymphocyte ratio, $d N L R$ derived neutrophil to lymphocyte ratio, $H b$ Hemoglobin concentration, $I G$ immature granulocyte, $L D H$ lactate dehydrogenase, $M C H$ mean corpuscular hemoglobin, $M C V$ mean corpuscular volume, $M L R$ monocyte to lymphocyte ratio, $M P R$ mean platelet volume to platelet ratio, $M P V$ mean platelet volume, $N L P R$ neutrophil to lymphocyte, platelet ratio, $N L R$ the neutrophil to lymphocyte ratio, $P L R$ platelet to lymphocyte ratio, $P T$ prothrombin time, $R D W$ red cell distribution width, SII systemic inflammation response index, and SIRI systemic inflammation response index, $T L C$ total leukocyte count
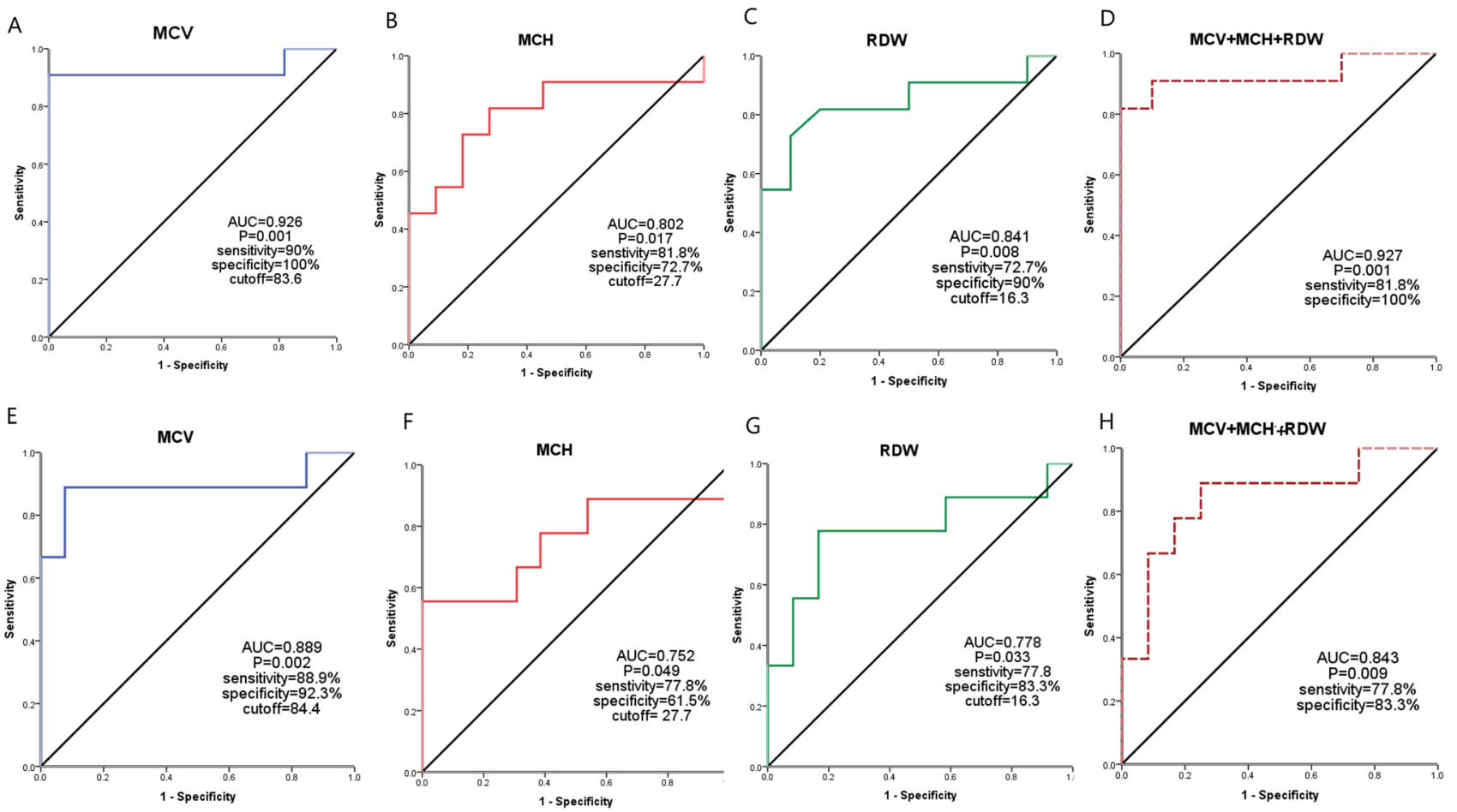

Fig. 4 ROC curve analysis of MCV, MCH, RDW and their combination for association with ICU admission (A, B, C, D) and increased incidence of mortality $(\mathbf{E}, \mathbf{F}, \mathbf{G}, \mathbf{H})$ in pediatric COVID-19 cancer patients

a prognostic predictor for patients with severe COVID-19 viral infection.

Taken together, we can conclude that cancer patients with COVID-19 have hematological and inflammatory indices different from that in COVID-19 non-cancer patients. Similarly, these inflammation indices are varied between pediatric and adult COVID-19 cancer patients. The increased level of both CRP/L and NLPR associated significantly with poor survival in adult COVID-19 cancer patients, while PLR associated significantly with ICU admission in pediatric COVID-19 cancer patients. Moreover, lymphopenia $<1.04 \times 10^{9} / 1$ will significantly predict ICU admission. The possibility of the integration of those inflammatory indices in peripheral blood picture could be a very useful method for early prediction and prognosis of COVID19 cancer patients. As these indices are very easy and rapid 
for calculations, as well as low-cost wise in low-income countries.

The MCV, MCH, RDW, and lymphopenia could be useful prognostic markers for poor outcome in COVID-19 pediatric cancer patients. However, these data should be verified on a larger number of patients including adult, pediatric, cancer, and non-cancer patients with COVID-19 infection for further confirmation.

Acknowledgements This work was supported by Cairo University, Fund No. 10/2020.

\section{Declarations}

Conflict of interest All authors declare that there is no possible conflict of interest.

Ethical approval The manuscript protocol had been approved by the institutional review board (IRB) committee of the National Cancer institute, which is in concordance with 2011 Declaration of Helsinki.

Informed consent A written informed consent had been obtained from all participant patients before inclusion in the study.

\section{References}

1. WHO. Coronavirus disease 2019 (COVID-19) Situation Report - 76 2020. https://www.who.int/docs/defaultsource/coronaviruse/ situation-reports/20200405-sitrep76-covid-19.pdf?sfvrsn=6ecf0 977_2. Accessed 6 Apr 2020.

2. Moujaess E, Kourie HR, Ghosn M. Cancer patients and research during COVID-19 pandemic: a systematic review of current evidence. Crit Rev Oncol Hematol. 2020;150:102972.

3. Guan WJ, Liang WH, Zhao Y, Liang HR, Chen ZS, et al. Comorbidity and its impact on 1590 patients with COVID-19 in China: a nationwide analysis. Eur Respir J. 2020;55(5):2000547.

4. Liang W, Guan W, Chen R, Wang W, Li J, et al. Cancer patients in SARS-CoV-2 infection: a nationwide analysis in China. Lancet Oncol. 2020;21(3):335-7.

5. Huang C, Wang Y, Li X, Ren L, Zhao J, Hu Y, Zhang L, Fan G, $\mathrm{Xu}$ J, Gu X. Clinical features of patients infected with 2019 novel coronavirus in Wuhan, China. Lancet. 2020;395(10223):497-506.

6. Guan WJ, Ni ZY, Hu Y, Liang WH, Ou CQ, et al. China medical treatment expert group for Covid-19. Clinical characteristics of coronavirus disease 2019 in China. N Engl J Med. 2020;382(18):1708-20. https://doi.org/10.1056/NEJMoa2002032.

7. Wang D, Hu B, Hu C, Zhu F, Liu X, Zhang J, Wang B, Xiang $\mathrm{H}$, Cheng Z, Xiong Y. Clinical characteristics of 138 hospitalized patients with 2019 novel coronavirus-infected pneumonia in Wuhan. China JAMA. 2020;323(11):1061-9.

8. Zhu N, Zhang D, Wang W, Li X, Yang B, Song J, Zhao X, Huang B, Shi W, Lu R, et al. A novel coronavirus from patients with pneumonia in China. N Engl J Med. 2019;2020:10-1056.

9. Rokni M, Ghasemi V, Tavakoli Z. Immune responses and pathogenesis of SARS-CoV-2 during an outbreak in Iran: comparison with SARS and MERS. Rev Med Virol. 2020;30(3):e2107.

10. Ying H, Deng Q, He B, Pan Y, Wang F, Sun H, Chen J, Liu X, Wang $S$. The prognostic value of preoperative NLR, d-NLR, PLR and LMR for predicting clinical outcome in surgical colorectal cancer patients. Med Oncol (Northwood, Lond, Engl). 2014;31(12):305.

11. Usul E, Şan İ, Bekgöz B, Şahin A. Role of hematological parameters in COVID-19 patients in the emergency room. Biomark Med. 2020;14(13):1207-15.

12. Peng J, Qi D, Yuan G, Deng X, Mei Y, Feng L, Wang D. Diagnostic value of peripheral hematologicmarkers for coronavirus disease 2019 (COVID-19): a multicenter, cross-sectional study. J Clin Lab Anal. 2020;34:e23475.

13. Yang A-P, Liu J-P, Tao W-Q, Li H-M. The diagnostic and predictive role of NLR, d-NLR and PLR inCOVID-19 patients. Int Immunopharmacol. 2020;84:106504.

14. Longbottom ER, Torrance HDT, Owen HC, Fragkou PC, Hinds CJ, Pearse RM, et al. Features of postoperative immune suppression are reversible with interferon gamma and independent of interleukin-6 pathways. Ann Surg. 2016;264:370-7.

15. Sica A, Massarotti M. Myeloid suppressor cells in cancer and autoimmunity. J Autoimmun. 2017;85:117-25.

16. World Health Organization. Clinical management of severe acute respiratory infection (SARI) when COVID-19 disease is suspected: interim guidance. Geneva: World Health Organization; 2020

17. Madhusoodhan PP, Pierro J, Musante J, Kothari P, Gampel B, Appel B, Levy A, et al. Characterization of COVID-19 disease in pediatric oncology patients: the New York-New Jersey regional experience. Pediatr Blood Cancer. 2021;68(3):e28843.

18. Fois AG, Paliogiannis P, Scano V, Cau S, Babudieri S, Perra R, Ruzzittu G, Zinellu E, Pirina P, Carru C, Arru LB, Fancellu A, Mondoni M, Mangoni AA, Zinellu A. The systemic inflammation index on admission predicts in-hospital mortality in COVID-19 patients. Molecules. 2020;25(23):5725.

19. Albarrán-Sánchez A, González-Ríos RD, Alberti-Minutti P, Noyola-García ME, Contreras-García CE, Anda-Garay JC, Martínez-Ascencio LE, Castillo-López DJ, Reyes-Naranjo LA, Guízar-García LA, Flores-Padilla G, Ramírez-Rentería C. Association of neutrophil-to-lymphocyte and lymphocyte-to-Creactive protein ratios with COVID-19-related mortality. Gac Med Mex. 2020;156(6):553-8.

20. Rokni M, Ahmadikia K, Asghari S, Mashaei S, Hassanali F. Comparison of clinical, para-clinical and laboratory findings in survived and deceased patients with COVID-19: diagnostic role of inflammatory indications in determining the severity of illness. BMC Infect Dis. 2020;20(1):869.

21. Liu J, Li S, Zhang S, Liu Y, Ma L, Zhu J, Xin Y, Wang Y, Yang C, Cheng Y. Systemic immune-inflammation index, neutrophil-to-lymphocyte ratio, platelet-to-lymphocyte ratio can predict clinical outcomes in patients with metastatic nonsmall-cell lung cancer treated with nivolumab. J Clin Lab Anal. 2019;33(8):e22964.

22. Zhang W, Wang R, Ma W, Wu Y, Maskey N, et al. Systemic immune-inflammation index predicts prognosis of bladder cancer patients after radical cystectomy. Ann Transl Med. 2019;7(18):431.

23. Huang H, Liu Q, Zhu L, Zhang Y, Lu X, Wu Y, Liu L. Prognostic value of preoperative systemic immune-inflammation index in patients with cervical cancer. Sci Rep. 2019;9(1):3284.

24. Mehta V, Goel S, Kabarriti R, et al. Case fatality rate of cancer patients with COVID-19 in a New York Hospital System. Cancer Discov. 2020;10(7):935-76.

25. Atkins $\mathrm{S}, \mathrm{He}$ F. Chemotherapy and beyond: infections in the era of old and new treatments for hematologic malignancies. Infect Dis Clin North Am. 2019;33(2):289-309.

26. Williamson EJ, Walker AJ, Bhaskaran K, et al. Factors associated with COVID-19 death in 17 million patients using OpenSAFELY. Nature. 2020;584:430-6. 
27. Ullah W, Basyal B, Tariq S, Almas T, Saeed R, et al. Lymphocyteto-C-reactive protein ratio: a novel predictor of adverse outcomes in COVID-19. J Clin Med Res. 2020;12(7):415-22.

28. Acar E, Demir A, Yıldırım B, Kaya MG, Gökçek K. The role of hemogram parameters and C-reactive protein in predicting mortality in COVID-19 infection. Int J Clin Pract. 2021;75(7):e14256.

29. Chau VQ, Oliveros E, Mahmood K, Singhvi A, Lala A, Moss N, Gidwani U, Mancini DM, Pinney SP, Parikh A. The imperfect cytokine storm: severe COVID-19 with ARDS in a patient on durable LVAD support. JACC Case Rep. 2020;2(9):1315-20.

30. Cossarizza A, Gibellini L, De Biasi S, Lo Tartaro D, Mattioli M, et al. Handling and processing of blood specimens from patients with COVID-19 for safe studies on cell phenotype and cytokine storm. Cytometry A. 2020;97(7):668-73.

31. Ying HQ, Deng QW, He BS, Pan YQ, Wang F, et al. The prognostic value of preoperative NLR, d-NLR, PLR and LMR for predicting clinical outcome in surgical colorectal cancer patients. Med Oncol. 2014;31(12):305.

32. Ruan Q, Yang K, Wang W, Jiang L, Song J. Clinical predictors of mortality due to COVID-19 based on an analysis of data of 150 patients from Wuhan, China. Intensive Care Med. 2020. https:// doi.org/10.1007/s00134-020-05991-x.

33. Paces J, Strizova Z, Smrz D, Cerny J. COVID-19 and the immune system. Physiol Res. 2020;69(3):379-88.

34. Lee RJ, Wysocki O, Bhogal T, Shotton R, Tivey A, et al. Longitudinal characterisation of haematological and biochemical parameters in cancer patients prior to and during COVID-19 reveals features associated with outcome. ESMO Open. 2021;6(1):100005.

35. Feng X, Li S, Sun Q, Zhu J, Chen B, Xiong M, Cao G. Immuneinflammatory parameters in COVID-19 cases: a systematic review and meta-analysis. Front Med (Lausanne). 2020;9(7):301.

36. van den Broek T, Borghans JAM, van Wijk F. The full spectrum of human naive T cells. Nat Rev Immunol. 2018;18:363-73.

37. Prendergast AJ, Klenerman P, Goulder PJ. The impact of differential antiviral immunity in children and adults. Nat Rev Immunol. 2012;12:636-48.

38. Dong Y, Mo X, Hu Y, Qi X, Jiang F, Jiang Z, Tong S. Epidemiology of COVID-19 among children in China. Pediatrics. 2020;145(6):e20200702.
39. Böncüoğlu E, Coşkun M, Kıymet E, Öztürk Atasoy T, Şahinkaya S, et al. Can laboratory findings predict pulmonary involvement in children with COVID-19 infection? Pediatr Pulmonol. 2021;56(8):2489-94.

40. Henry BM, Benoit SW, de Oliveira MHS, Hsieh WC, Benoit J, et al. Laboratory abnormalities in children with mild and severe coronavirus disease 2019 (COVID-19): a pooled analysis and review. Clin Biochem. 2020;81:1-8.

41. Qu R, Ling Y, Zhang YH, Wei LY, Chen X, Li XM, Liu XY, Liu HM, Guo Z, Ren H, Wang Q. Platelet-to-lymphocyte ratio is associated with prognosis in patients with coronavirus disease- 19 . J Med Virol. 2020;92(9):1533-41.

42. Ma H, Ye Q, Ding W, Jiang Y, Wang M, Niu Z, et al. Can clinical symptoms and laboratory results predict $\mathrm{CT}$ abnormality? Initial findings using novel machine learning techniques in children With COVID-19 infections. Front Med (Lausanne). 2021;8:699984.

43. Nazarullah A, Liang C, Villarreal A, Higgins RA, Mais DD. Peripheral blood examination findings in SARS-CoV-2 infection. Am J Clin Pathol. 2020;154(3):319-29.

44. Kaur G, Sandeep F, Olayinka O, Gupta G. Morphologic changes in circulating blood cells of COVID-19 patients. Cureus. 2021;13(2):e13416.

45. Berber I, Cagasar O, Sarici A, Berber NK, Aydogdu I, et al. Peripheral blood smear findings of COVID-19 patients provide information about the severity of the disease and the duration of hospital stay. Mediterr J Hematol Infect Dis. 2021;13(1):e2021009.

46. Wang C, Zhang H, Cao X, Deng R, Ye Y, Fu Z, Gou L, Shao F, Li J, Fu W, Zhang X, Ding X, Xiao J, Wu C, Li T, Qi H, Li C, Lu Z. Red cell distribution width (RDW): a prognostic indicator of severe COVID-19. Ann Transl Med. 2020;8(19):1230.

Publisher's Note Springer Nature remains neutral with regard to jurisdictional claims in published maps and institutional affiliations. 